\title{
Endoscopic papillectomy: a novel approach to difficult cannulation
}

\author{
R J Farrell, M I Khan, N Noonan, K O’Byrne, P W N Keeling
}

\begin{abstract}
Background-Selective cannulation of the biliary and pancreatic ducts is considered to be the most difficult and rate limiting aspect of diagnostic endoscopic retrograde cholangiopancreatography (ERCP).

Aims/Methods-A novel technique for difficult cannulation is described and its potential role in relieving malignant duodenal obstruction secondary to ampullary carcinoma. A diagnostic endoscopic papillectomy was performed in 10 patients in whom previous attempts at cannulation had failed. Five patients had exophytic ampullary carcinomas, one had carcinoma of the head of pancreas, two had an oedematous ampulla secondary to low common bile duct stones, while two had protuberant ampullae with ectopic orifices. The technique entails snaring the ampulla flush with the duodenal wall using a polypectomy snare and in a similar fashion to polypectomy removing the ensnared ampulla with diathermy using a coagulation current. The underlying exposed ducts can then be cannulated while the ensnared ampulla can be retrieved to aid histological diagnosis.
\end{abstract}

Results-Successful cannulation was achieved in all 10 cases with significant haemorrhage in one patient $(10 \%)$. Four of the snared ampullary carcinomas $(80 \%)$ were retrieved enabling a histological diagnosis to be made.

Conclusions-This study demonstrates the potential role for endoscopic papillectomy as a means of cannulation in difficult circumstances, however larger comparative studies are required.

(Gut 1996; 39: 36-38)

Keywords: endoscopic papillectomy, endoscopic retrograde cholangiopancreatography, ampullary carcinoma, pancreatic carcinoma, ampulla of Vater.

Departments of Clinical Medicine, and Gastroenterology, Trinity College, St James's Hospital, Dublin, Ireland

R J Farrell

M I Khan

N Noonan

K O'Byrne

$P$ W N Keeling

Correspondence to: Dr R J Farrell, Departments of Clinical Medicine and Gastroenterology, St James'

Accital, Dublin 7, Ireland.

19 January 1996
The big bulky ampulla may be a particular problem in cannulation. Frequently, the opening is obscured by tumour. In addition, protuberant ampullae at ectopic locations often prove difficult to cannulate. In these cases, we describe a novel technique. This technique entails snaring the ampulla flush with the duodenal wall using a polypectomy snare and in a similar fashion to polypectomy removing the ensnared ampulla with diathermy using a coagulation current. The underlying exposed ducts can then be cannulated while the ensnared ampulla can be retrieved to aid histological diagnosis.
The role of endoscopic diathermic snare papillectomy has been previously described as an effective means of removing benign adenomas of the ampulla of Vater ${ }^{1}$ as well as debulking obstructing large malignant ampullary tumours ${ }^{2}$ thus avoiding the need for extensive bypass surgery and providing an effective alternative to surgical papillectomy ${ }^{3}$ and transduodenal surgical resection. This study highlights a novel role of endoscopic papillectomy as a means of achieving difficult cannulation in bulky ampullae. Normally cannulation may be achieved with a standard $6 \mathrm{Q}$ catheter. Failing this fine tipped or metal tipped catheters or papillotomes may be used. If cannulation is still not achieved a pre-cut or needle-knife papillotomy may be used to aid exposure to the biliary and pancreatic ductal orifices. Unfortunately these procedures are associated with increased morbidity particularly perforation and haemorrhage ${ }^{4}$ thence the potential role for endoscopic papillectomy as a means of cannulation in difficult circumstances.

\section{Methods}

\section{Patients}

We performed an endoscopic papillectomy in 10 patients in whom previous attempts at cannulation had failed. Five patients had exophytic ampullary carcinomas, including a large fungating ampullary carcinoma that was obstructing the duodenal lumen, one had a head of pancreas carcinoma, two had an oedematous ampulla secondary to low common bile duct stones, while two had protuberant ampullae with ectopic orifices. The mean age was 72.3 years with an age range of 45 to 78 years including six females and four males. All 10 patients had had previous endoscopic retrograde cholangiopancreatography (ERCP) with failed ampullary cannulation including five patients who had had a previous pre-cut papillotomy and three who had a previous needle-knife papillotomy that failed to aid cannulation. The mean follow up was 13.2 months, range 7-21 months. All patients had protuberant ampullae. Platelet count and coagulation indices were normal and each patient received conventional antibiotic prophylaxis. Continuous oxygen was delivered via nasal prongs, while their pulse rate and oxygen saturation was monitored by pulse oximeter (Novemetrix). ERCP was performed under intravenous sedation with midazolam 4-10 $\mathrm{mg}$ and pethidine $50-150 \mathrm{mg}$. Seven patients also received hyoscine $20-40 \mathrm{mg}$ and glucagon $0.5-1.5 \mathrm{IU}$ to reduce excessive duodenal muscle spasm (Table). 
Patient details

\begin{tabular}{ll}
\hline Patients & $\begin{array}{c}\text { Endoscopic } \\
\text { papillectomy }\end{array}$ \\
\hline Number & 10 \\
Male/female & $4 / 6$ \\
Mean age (y) & $72 \cdot 3$ \\
Range (y) & $45-78$ \\
Reason for failed cannulation: & 5 \\
Ampullary carcinoma & 1 \\
Invading pancreatic carcinoma & \\
Oedematous ampulla (common bile duct & 2 \\
stones) & 2 \\
Protuberant ampulla with ectopic orifice & \\
Previous cannulation technique: & 5 \\
Pre-cut papillotomy & 3 \\
Needle-knife papillotomy & $10(100 \%)$ \\
Biliary cannulation & $10(100 \%)$ \\
Pancreatic cannulation & $13 \cdot 2$ \\
Mean follow up (months) & $7-21$ \\
Follow up range (months) & \\
Complications: & \\
Short-term: & 1 \\
Haemorrhage & 0 \\
Pancreatitis & 0 \\
Perforation & \\
Long term: & 0 \\
Pancreatitis & 0 \\
Ductal stenosis & \\
\hline
\end{tabular}

Endoscopic papillectomy technique

Diagnostic JFIT-20 side viewing endoscopes were used. These enabled a 5-French disposable oval or hexagon snare to be inserted through the biopsy channel into the duodenal lumen. The ampulla is then snared flush with the duodenal wall once the entire base of the ampulla is encircled (Figure). Analogous to polypectomy of colon adenomas, the ampulla of Vater/ampullary tumour is excised in a radical fashion to the level of the muscularis

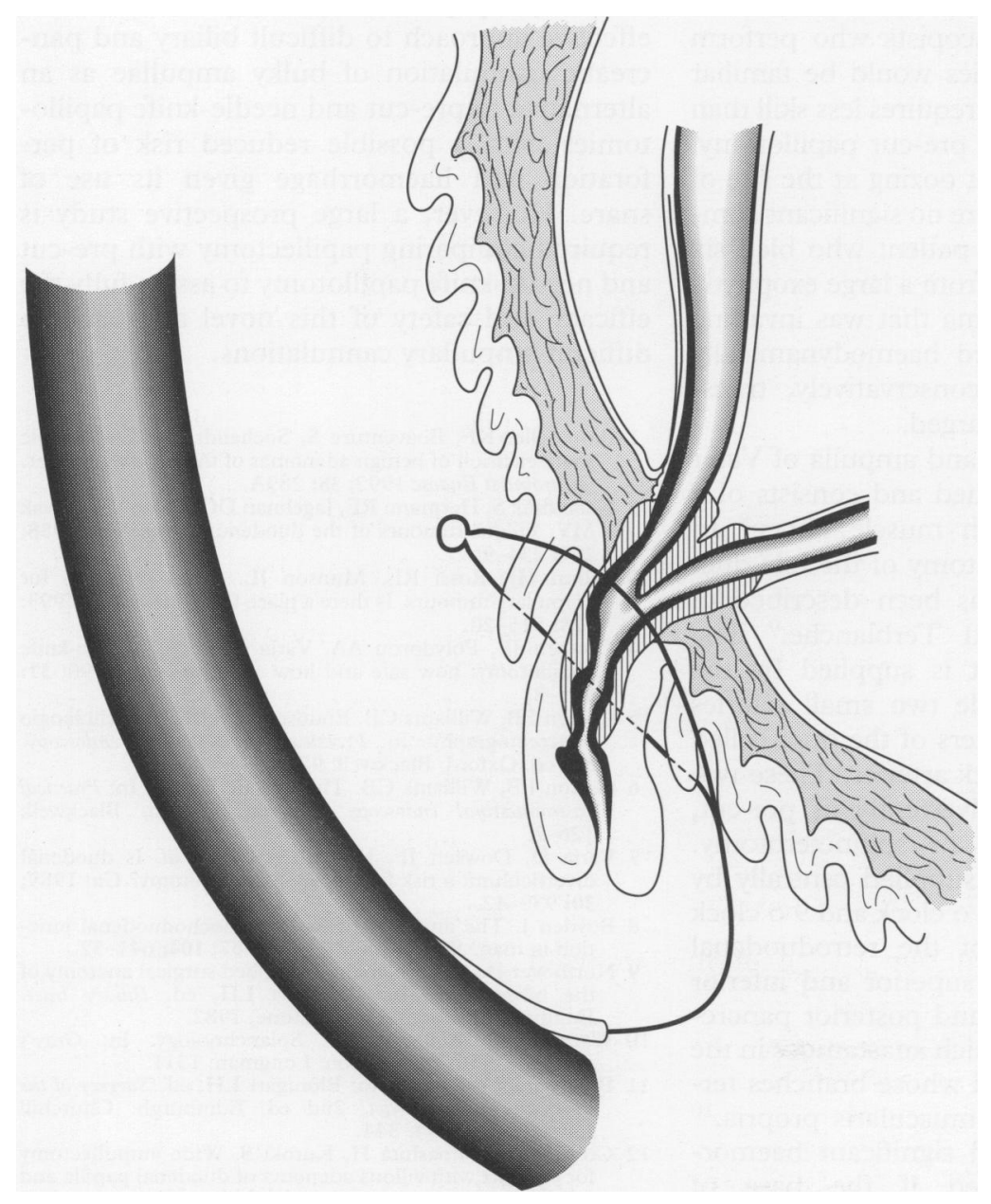

Snared protuberant ampulla. propria using a 3.5 coagulation current with a standard PSD 10 Olympus diathermy machine. While the common or external sphincter is excised at papillectomy both internal sphincters (biliary and pancreatic) are preserved while the transampullary septum and both ductal orifices are exposed and relatively easy to cannulate using the standard $6 Q$ catheter. Base biopsy specimens can also be taken where an ampullary carcinoma is suspected to assess possible invasion.

\section{Results}

The average duration of the procedure including retrieval took 20-30 minutes. All patients were admitted electively after papillectomy for 24 hours. Successful biliary and pancreatic duct cannulation was achieved in all 10 cases with significant haemorrhage in one patient. This patient bled six hours after papillectomy from a large exophytic head of pancreas carcinoma, which was invading the ampulla and dropped his haemoglobin by $3 \mathrm{~g}$ but remained haemodynamically stable. Repeat ERCP confirmed a large haemorrhagic necrotic malignant ulcer secondary to underlying pancreatic tumour invasion. He required transfusion with four units of blood and was discharged four days later. He subsequently died two months later from metastatic disease. None of the patients suffered from pancreatitis after papillectomy. Four of the snared ampullary carcinomas ( $80 \%)$ were retrieved enabling a histological diagnosis to be made. The fifth patient had a large fungating ampullary carcinoma, which prohibited cannulation and thence biliary decompression. There was radiological evidence of liver metastases. After papillectomy the biliary tract was decompressed but the resected ampulla was not retrieved. In all five cases base biopsy specimens were taken confirming invasion. Two cases had endoscopic sphincterotomies performed after papillectomy to aid biliary stenting. In both cases where there was an oedematous ampulla secondary to low common bile duct stones, the common bile duct was successfully cannulated after papillectomy, a sphincterotomy was performed, and the stones removed by balloon clearance. In a further two patients who had protuberant ampullae with ectopic orifices, one of which had a large adjacent diverticulum, subsequent biliary cannulation was possible confirming a normal biliary tree in one case and choledocholithiasis in the other, which was cleared successfully after sphincterotomy. To date, no longterm adverse effects have been reported in any of the patients currently alive with no evidence of stenosis of biliary or pancreatic ductal orifices in surviving patients.

\section{Discussion}

Selective cannulation of the biliary and pancreatic ducts is considered to be the most difficult and rate limiting aspect of diagnostic ERCP. Biliary/pancreatic duct cannulation is

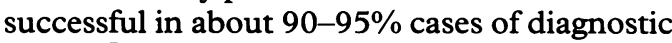
ERCP. ${ }^{5}$ Failed cannulation not only proves time consuming for the endoscopist and 
endoscopy nursing staff but leads to prolonged sedation and lengthier hospital stays for the patient in addition to further burdening already over-run ERCP lists as repeat ERCPs have to be rescheduled. Furthermore, difficult cannulations are associated with increased morbidity for the patient as pre-cut or needleknife may be used to aid exposure to the biliary and pancreatic ductal orifices. The success and safety of pre-cut and needle-knife papillotomy is very much operator dependent and depends foremost upon proper orientation of the precut or needle-knife incision in the direction of the presumed course of the bile duct. In inexperienced hands, pre-cut papillotomy is more dangerous than standard sphincterotomy as it is an uncontrolled incision without having achieved deep biliary cannulation. ${ }^{6}$ These procedures have a risk of haemorrhage in addition to the inherent risks of perforation. It is notable that this series included a patient with an exophytic ampulla located adjacent to a large duodenal diverticulum, a situation associated with a higher risk of perforation if pre-cut papillotomy or sphincterotomy are performed. ${ }^{7}$ While the risk of pancreatitis is theoretically increased after papillectomy, the fact that none of our patients had pancreatitis may relate to the fact that the internal pancreatic sphincter is preserved.

Our results, although admittedly with a small series show that endoscopic papillectomy achieved successful cannulation of both biliary and pancreatic duct orifices in all 10 patients $(100 \%)$. The procedure is not difficult to perform and most endoscopists who perform colonoscopic polypectomies would be familiar with the technique, which requires less skill than a pre-cut or needle-knife pre-cut papillotomy. Apart from some transient oozing at the site of the papillectomy, there were no significant complications except a single patient who bled six hours postampullectomy from a large exophytic head of pancreas carcinoma that was invading the ampulla but remained haemodynamically stable. He was treated conservatively, transfused, and was duly discharged.

The sphincter of Oddi and ampulla of Vater has been thoroughly studied and consists of a unique cluster of smooth muscle fibres. ${ }^{8}$ In addition, the vascular anatomy of the bile duct and ampulla of Vater has been described in detail by Northover and Terblanche. ${ }^{9}$ The lower common bile duct is supplied by the retroduodenal artery while two small arteries run along the lateral borders of the duct called the 3 o'clock and 9 o'clock arteries. These two arteries may be cut inadvertently at pre-cut, needle-knife papillotomy or sphincterotomy. The ampulla of Vater is supplied centrally by terminal branches of the 3 o'clock and 9 o'clock arteries, side branches of the retroduodenal artery in addition to the superior and inferior branches of the anterior and posterior pancreaticoduodenal arteries, which anastamose in the region of the ampulla and whose branches terminate in the ampullary muscularis propria. ${ }^{10}$ Thus vascular injury and significant haemorrhage can be minimised if the base of the ampulla is fully ensnared, flush with the duodenal wall before diathermy. The fact that the only major haemorrhage was in a patient with underlying head of pancreas carcinoma that was invading the ampulla is significant. This may suggest that future papillectomies for ampullary tumours should be confined to malignancies originating in the ampulla as head of pancreas carcinoma may disrupt the normal vascular anatomy of the periampullary region ${ }^{11}$ and thus contribute to blood loss. A further limitation of endoscopic papillectomy belies the fact that a significant number of failed ampullary cannulations are because of flat, small, endophytic ampullae. Unfortunately, these are unsuitable for papillectomy and in our opinion are best cannulated after pre-cut or needle-knife papillotomies.

In addition to its novel role in aiding cannulation, this series also highlights the role of endoscopic papillectomy as an effective means of debulking obstructing large malignant ampullary tumours and thus avoiding the need for extensive bypass surgery. Endoscopic papillectomy also has a role as an effective alternative to wide surgical papillectomy ${ }^{12}$ in the definitive management of benign adenomas of the ampulla of Vater. In our series four of the snared ampullary carcinomas (80\%) were retrieved enabling a successful histological diagnosis to be made with base biopsy specimens confirming invasion in all cases.

Our experience shows that in addition to its established role in palliatively debulking large obstructing malignant ampullary tumours, endoscopic papillectomy may provide a novel effective approach to difficult biliary and pancreatic cannulation of bulky ampullae as an alternative to pre-cut and needle-knife papillotomies with a possible reduced risk of perforation and haemorrhage given its use of snare. However, a large prospective study is required comparing papillectomy with pre-cut and needle-knife papillotomy to assess fully the efficacy and safety of this novel approach to difficult ampullary cannulations.

1 Binmoeller KF, Boaventure S, Soehendra N. Endoscopic snare excision of benign adenomas of the papilla of Vater. Gastrointest Endosc 1992; 38: 289A

2 Galandiuk S, Hermann RE, Jagelman DG, Fazio VW, Sivak MV. Villous tumours of the duodenum. Ann Surg 1988; 207: 234-9.

3 Asbun HJ, Rossi RL, Munson JL. Local resection for ampullary tumours. Is there a place for it? Arch Surg 1993; 128: 515-20.

4 Dowsett JF, Polydorou AA, Varia D, et al. Needle-knife papillotomy: how safe and how effective? Gut 1990; 31: 905-8

5 Cotton PB, Williams CB. Endoscopic retrograde cholangio pancreatography. In: Practical gastrointestinal endoscopy. 3rd ed. Oxford: Blackwell: 92 .

6 Cotton PB, Williams CB. Therapeutic ERCP. In: Practical gastrointestinal endoscopy. 3rd ed. Oxford: Blackwell: 126-7.

7 Varia D, Dowsett JF, Hatfield ARW, et al. Is duodenal diverticulum: a risk factor for sphincterotomy? Gut 1989; 30: 939-42.

8 Boyden J. The anatomy of the choledochoduodenal junction in man. Surg Gynecol Obstet 1957; 104: 641-52.

9 Northover JMA, Terblanche J. Applied surgical anatomy of the biliary tree. In: Blumgart LH, ed. Biliary tract.
Edinburgh: Churchill Livingstone, 1982 .

10 Warwick R, Williams PL. Splanchnology. In: Gray's Anatomy. 35th ed. London: Longman: 1311.

11 Biliary tract radiology. In: Blumgart LH, ed. Surgery of the liver and biliary tract. 2nd ed. Edinburgh: Churchill Livingstone, 1994: 344.

12 Chijiiwa K, Yamashita $\mathrm{H}$, Kuroki S. Wide ampullectomy for patients with villous adenoma of duodenal papilla and follow-up results of pancreaticobiliary tract. Int Surg 1994; 79: 178-82. 